\title{
Effects of Lyophilized Colostrum and Different Colostrum Feeding Regimens on Passive Transfer of Immunoglobulin G in Majorera Goat Kids
}

\author{
N. Castro, ${ }^{1}$ J. Capote, ${ }^{2}$ S. Álvarez, ${ }^{2}$ and A. Argüello ${ }^{1 *}$ \\ ${ }^{1}$ Department of Animal Science, Las Palmas de Gran Canaria University, Arucas 35416, Spain \\ ${ }^{2}$ Canary Agronomic Science Institute, La Laguna, Tenerife, Spain
}

\begin{abstract}
Three experiments were conducted including $180 \mathrm{Ma}-$ jorera kids. In the first experiment, the effect of use of lyophilized colostrum vs. frozen colostrum on immunoglobulin G (IgG) blood serum concentration was evaluated. Kids $(n=40)$ received the same management and IgG mass [3368 mg/kg of body weight (BW)] during the colostrum feeding period. The IgG in blood serum of kids from the lyophilized colostrum group was greater than that for kids that received frozen colostrum. The second experiment evaluated the effect of total IgG ingested by kids $(n=60)$ on IgG in blood serum during the colostrum feeding period. Three groups of animals received 3368, 1684, and $842 \mathrm{mg}$ of $\mathrm{IgG} / \mathrm{kg}$ of BW in 4 feedings for $2 \mathrm{~d}$ [high IgG concentration (H-IgG), medium IgG concentration (M-IgG), and low-IgG concentration (L-IgG), respectively]. The IgG blood serum in the kids that received $\mathrm{H}-\mathrm{IgG}$ was greater than in the other 2 treatment groups, and no statistical differences were found for IgG in blood serum of kids that received either M-IgG or L-IgG. The third experiment evaluated the effect of timing of lyophilized colostrum meals on IgG blood serum concentration. Four groups of kids $(n=80)$ were used. Two groups received $1684 \mathrm{mg}$ of IgG/kg of BW (higher level-1 d and higher level-2 d) and the other 2 groups received 842 $\mathrm{mg}$ of IgG/kg of BW (lower level-1 d and lower level-2 d). Two groups received 2 feedings in $1 \mathrm{~d}$, and the other 2 groups received 4 feedings over a 2 -d period, as denoted. Higher level-1 d kids had greater IgG blood serum concentration than the higher level-2 d kids, and no statistical differences were found between lower level-1 $d$ and lower level-2 d kids.
\end{abstract}

(Key words: goat kid, colostrum, lyophilized, immunoglobulin G)

Abbreviation key: CAEV = caprine arthritis encephalitis, H-IgG = high concentration (3368 mg/kg of BW) of

Received October 7, 2004

Accepted June 13, 2005.

Corresponding author: A. Argüello; e-mail: aarguello@dpat. ulpgc.es.
IgG, HL-1d = high concentration of IgG in lyophilized paste in $1 \mathrm{~d}, \mathbf{H L}-\mathbf{2 d}=$ high concentration of IgG in lyophilized paste in $2 \mathrm{~d}$, L-IgG = low concentration of IgG (842 $\mathrm{mg} / \mathrm{kg}$ of BW), LL-1d = low concentration of IgG in lyophilized paste in $1 \mathrm{~d}$, LL-2d = low concentration of IgG in lyophilized paste in $2 \mathrm{~d}$, M-IgG = medium concentration of $\operatorname{IgG}(1684 \mathrm{mg} / \mathrm{kg}$ of BW).

\section{INTRODUCTION}

To minimize or even annul the mother-kid link, which is established in the first hours after birth (Ramírez et al., 1996) in artificial rearing management, the kids must be removed after parturition. This practice facilitates the acceptance of being bottle-fed, thus improving the adoption of artificial rearing. The latter system is of particular interest in areas where diseases such as caprine arthritis encephalitis (CAEV) are present, as colostrum is one of the direct means of transmission (Guerrault, 1990). To control CAEV, the colostrum has to be pasteurized. This procedure, however, reduces the colostrum IgG concentration (Argüello et al., 2003); therefore, it can be argued that lyophilized colostrum could be more effective, as it maintains a higher IgG concentration. In ruminants, the placenta impedes the transfer of Ig from the dam to the fetus; consequently, the consumption of colostrum by the progeny of these species holds a fundamental role in the acquisition of immunity. Some studies have found lyophilized colostrum to be stable, easy to handle, and suitable for the passive immunization of calves (Klobasa et al., 1998; Husu et al., 1993). Dos Santos et al. (1994) found no relationship between colostral IgG concentration and serum IgG concentration in 1-d-old kids. Chen et al. (1999) observed significant differences in serum IgG concentrations between kids fed colostrum with high or low protein concentration (20 and $10 \mathrm{~g} / \mathrm{dL}$ ). In calves, the IgG colostrum concentration is more important than the quantity of colostrum fed if the total IgG colostrum fed was the same. Stott and Fellah (1983) observed that IgG serum was higher in calves fed $1 \mathrm{~L}$ of colostrum with $60 \mathrm{mg} /$ $\mathrm{mL}$ of IgG than in those fed $2 \mathrm{~L}$ of colostrum with 30 $\mathrm{mg} / \mathrm{mL}$ of IgG. The relationship between the IgG fed and 
IgG in the calf's blood was linear according to Stott and Fellah (1983). In kids of the Majorera breed, the quantity of IgG consumed presented a high positive correlation with IgG blood concentrations, particularly in the first $72 \mathrm{~h}$ of the animal's life, but this correlation diminished significantly at $84 \mathrm{~h}$ (Argüello et al., 2004b).

No literature has been found related to the use of lyophilized goat colostrum in kids. The present experiments will be the first to approach the use of this technology in goat kids and will try to explain how the principal effects (IgG colostrum concentration, timing of lyophilized colostrum meals, and amount of IgG fed) will affect the IgG serum blood concentration in kids.

The objectives of this experiment were to determine the effect of lyophilized colostrum fed, the effect of total IgG fed to the kids, and the effect of the timing of lyophilized colostrum meals on IgG blood serum during the colostrum feeding period.

\section{MATERIALS AND METHODS}

Three different experiments were designed. A colostrum pool was made from fresh goat colostrum (16.84 $\mathrm{mg}$ of $\mathrm{IgG} / \mathrm{mL}$ of colostrum), $4 \mathrm{~L}$ of which were frozen $\left(-20^{\circ} \mathrm{C}\right)$ and $30 \mathrm{~L}$ were lyophilized, producing a colostrum powder with an IgG concentration of $61.041 \mathrm{mg}$ of IgG/g. This pool was used to feed the kids in the 3 experiments. Lyophilized colostrum pastes were prepared by mixing lyophilized colostrum powder plus sterilized hot water $\left(40^{\circ} \mathrm{C}\right)$ in accordance with the method used by Argüello et al. (2003). Majorera kids were used for these experiments. The Majorera breed is a dairy goat with an average milk production of $546 \mathrm{~L} / 210 \mathrm{~d}$. The Majorera goat kids have an average birth weight of $3.50 \mathrm{~kg}$ for males and $3.15 \mathrm{~kg}$ for females (Capote et al., 1992). The management of the kids before starting the experiments was the same. Immediately after birth, they were separated from their mothers and dried. Their umbilical cords were disinfected, and they were weighed, identified, and randomly distributed into groups with the same number of males and females. Frozen colostrum or lyophilized colostrum paste was administered by bottle-feeding at $2,14,26$, and $38 \mathrm{~h}$ postpartum depending on the experiment.

In the first experiment, the effect of feeding lyophilized colostrum vs. frozen colostrum on the IgG kid serum was evaluated. The 40 Majorera kids (20 males and 20 females) were randomly assigned to 2 groups. The frozen colostrum group and the lyophilized group were fed with their respective form of colostrum $2 \times / \mathrm{d}$ for $2 \mathrm{~d}$. Each feeding in both groups contained $842 \mathrm{mg}$ of $\mathrm{IgG} / \mathrm{kg}$ of BW according to the management system proposed by Argüello et al. (2004c). The total IgG received by both groups was $3368 \mathrm{mg}$ of $\mathrm{IgG} / \mathrm{kg}$ of BW. Each kid from the frozen colostrum group received $50 \mathrm{~mL}$ of thawed colostrum $/ \mathrm{kg}$ of BW per feeding. The frozen colostrum was thawed at room temperature and after that was warmed to $40^{\circ} \mathrm{C}$ (internal temperature) in microwave ovens (rotary microwave) in accordance with the system used by Argüello et al. (2003). The IgG concentration of the lyophilized colostrum paste was $22.88 \mathrm{mg}$ of IgG/g. Each kid in the lyophilized colostrum group received $36.80 \mathrm{~g}$ of lyophilized colostrum paste/kg of BW per feeding (Table 1).

In the second experiment, the effect of the total IgG received/kg of BW on IgG kid serum was evaluated. Sixty Majorera kids (30 males and 30 females) were randomly assigned to 3 groups. All groups were fed with lyophilized colostrum paste $2 \times / \mathrm{d}$ for $2 \mathrm{~d}$. The first group (high IgG concentration; H-IgG) was fed using a lyophilized colostrum paste with an IgG concentration of $22.88 \mathrm{mg}$ of IgG/g; each kid received $36.80 \mathrm{~g}$ of lyophilized colostrum paste/kg of BW per feeding, representing $842 \mathrm{mg}$ of IgG per feeding per $\mathrm{kg}$ of $\mathrm{BW}$. The total IgG received by the H-IgG kids was $3368 \mathrm{mg} / \mathrm{kg}$ of BW. The medium IgG concentration group (M-IgG) was fed using lyophilized colostrum paste with an IgG concentration of $11.44 \mathrm{mg}$ of $\mathrm{IgG} / \mathrm{g}$, and each kid from this group received 36.80 $\mathrm{g}$ of lyophilized colostrum paste/kg of BW per feeding, representing $421 \mathrm{mg}$ of $\mathrm{IgG}$ per feeding $/ \mathrm{kg}$ of BW. The total IgG received by the kids in the M-IgG group was $1684 \mathrm{mg} / \mathrm{kg}$ of BW. The final group (low concentration of IgG; L-IgG) was fed twice using lyophilized colostrum paste with an IgG concentration of $5.72 \mathrm{mg}$ of IgG/g. Each kid in this group received $36.80 \mathrm{~g}$ of lyophilized colostrum paste/kg of BW per feeding, representing $210.5 \mathrm{mg}$ of IgG per feeding $/ \mathrm{kg}$ of BW. The total IgG received by kids in the L-IgG concentration group was $842 \mathrm{mg} / \mathrm{kg}$ of BW.

In the third experiment, the effect of the timing of lyophilized colostrum meals per day on IgG kid serum was evaluated at $2 \mathrm{IgG}$ concentrations/kg of BW. Eighty Majorera kids (40 males and 40 females) were randomly assigned into 4 groups. The first group received lyophilized colostrum paste $2 \times / \mathrm{d}$ during $1 \mathrm{~d}$; this group was assigned as HL-1d (high concentration, $1 \mathrm{~d}$ ). The IgG concentration of the lyophilized colostrum paste was $22.88 \mathrm{mg}$ of IgG/g. Each HL-1d kid received $36.80 \mathrm{~g}$ of lyophilized colostrum paste/kg of BW per feeding, representing $842 \mathrm{mg}$ of IgG per feeding/kg of BW. The total IgG received by HL-1d kids was $1684 \mathrm{mg} / \mathrm{kg}$ of BW. The second high IgG concentration group received lyophilized colostrum paste $2 \times / d$ during $2 \mathrm{~d}$; this group was assigned as HL-2d (high IgG concentration, $2 \mathrm{~d}$ ). The IgG concentration of the lyophilized colostrum paste was $11.44 \mathrm{mg}$ of IgG/g. Each HL-2d kid received $36.80 \mathrm{~g}$ of lyophilized colostrum paste/kg of BW per feeding, representing $421 \mathrm{mg}$ of IgG per feedin/kg of BW. The total 
Table 1. Management and IgG amount received by kids receiving frozen and lyophilized colostrum. ${ }^{1}$

\begin{tabular}{|c|c|c|c|c|c|c|c|c|c|}
\hline & \multicolumn{2}{|c|}{ Experiment 1} & \multicolumn{3}{|c|}{ Experiment 2} & \multicolumn{4}{|c|}{ Experiment 3} \\
\hline & FG & LG & H-IgG & M-IgG & L-IgG & HL-1d & HL-2d & LL-1d & LL-2d \\
\hline Colos & 2 & 2 & 2 & 2 & 2 & 1 & 2 & 1 & 2 \\
\hline Feedings per $d$ & 2 & 2 & 2 & 2 & 2 & 2 & 2 & 2 & 2 \\
\hline Total feedings & 4 & 4 & 4 & 4 & 4 & 2 & 4 & 2 & 4 \\
\hline $\mathrm{IgG}, \mathrm{mg} / \mathrm{kg}$ of $\mathrm{BW}$ & 842 & 842 & 842 & 421 & 210.5 & 842 & 421 & 421 & 210.5 \\
\hline Total IgG fed, $\mathrm{mg} / \mathrm{kg}$ of BW & 3368 & 3368 & 3368 & 1684 & 842 & 1684 & 1684 & 842 & 842 \\
\hline
\end{tabular}

${ }^{1} \mathrm{FG}=$ Frozen colostrum group, LG = lyophilized colostrum group, HL-1d = high concentration of IgG in lyophilized paste in $1 \mathrm{~d}$, HL-2d = high concentration of IgG in lyophilized paste in $2 \mathrm{~d}$, LL-1d = low concentration of IgG in lyophilized paste in $1 \mathrm{~d}, \mathrm{LL}-2 \mathrm{~d}=$ low concentration of IgG in lyophilized paste in 2 $\mathrm{d}, \mathrm{H}-\mathrm{IgG}=$ high concentration of IgG in lyophilized paste, $\mathrm{M}-\mathrm{IgG}=$ medium concentration of IgG in lyophilized paste, and L-IgG = low concentration of IgG in lyophilized paste.

IgG received by the HL-2d kids was $1684 \mathrm{mg} / \mathrm{kg}$ of BW. The third group (low IgG concentration) received lyophilized colostrum paste $2 \times / \mathrm{d}$ in $1 \mathrm{~d}$; this group was assigned as LL-1d (low IgG concentration during $1 \mathrm{~d}$ ). The IgG concentration on lyophilized colostrum paste was 11.44 $\mathrm{mg}$ of IgG/g. Each LL-1d kid received $36.80 \mathrm{~g}$ of lyophilized colostrum paste/kg of BW per feeding, representing $421 \mathrm{mg}$ of IgG per feeding per $\mathrm{kg}$ of BW. The total IgG received by the LL-1d kids was $842 \mathrm{mg} / \mathrm{kg}$ of BW. The fourth group (also low IgG concentration) received lyophilized colostrum paste $2 \times / d$ during $2 \mathrm{~d}$; this group was assigned as LL-2d (low IgG concentration, $2 \mathrm{~d}$ ). The IgG concentration of the lyophilized colostrum paste was 5.72 $\mathrm{mg}$ of IgG/g. Each LL-2d kid received $36.80 \mathrm{~g}$ of lyophilized colostrum paste/kg of BW per feeding, representing $210.5 \mathrm{mg}$ of IgG per feeding $/ \mathrm{kg}$ of BW. Total IgG received by LL-2d kids was $842 \mathrm{mg} / \mathrm{kg}$ of BW.

The kids had no access to fresh water until $15 \mathrm{~d}$ of life.

To lyophilize goat colostrum, $500 \mathrm{~mL}$ of goat colostrum was frozen at $-80^{\circ} \mathrm{C}$ for $2 \mathrm{~d}$. Subsequently, bottles containing frozen colostrum were connected to the lyophilizer (Telstar Cryodos-80) for $5 \mathrm{~d}$. The vacuum level was $7.9 \times 10^{-2} \mathrm{mBa}$, and the temperature was $-55^{\circ} \mathrm{C}$.

Samples from the jugular vein were taken every $12 \mathrm{~h}$ from birth to $108 \mathrm{~h}$ postpartum to determine the IgG concentration in the kids' blood. The blood was introduced into a clotting tube and was centrifuged; the serum obtained was frozen at $-20^{\circ} \mathrm{C}$ until analysis. The IgG quantification was made using radial immunodiffusion in accordance with the method used by Mancini et al. (1965). The agar was prepared by adding $1 \mathrm{~L}$ of glycine buffer [pH 7; $7.5 \mathrm{~g}$ of glycine, $100 \mathrm{~mL}$ of EDTA $(0.4 M)$ in distilled water and adjusting the volume to $1 \mathrm{~L}$ ] to 20 $\mathrm{g}$ of agar. This suspension was placed in a boiling waterbath and stirred until the agar had dissolved, after which it was cooled to $60^{\circ} \mathrm{C}$. The antiserum (previously made by the inoculation of rabbits with goat IgG) or a suitable dilution of it made in a glycine buffer was heated to $55^{\circ} \mathrm{C}$, after which both solutions were mixed thoroughly, avoiding bubbling, with the aid of a pipette preheated to $60^{\circ} \mathrm{C}$. The antiserum-agar mixture was immediately poured into the petri dish with a final agar thickness of $0.3 \mathrm{~cm}$. The petri dish was sealed and stored at $4^{\circ} \mathrm{C}$ until use. Circular wells were punched in the gel, using a 3$\mathrm{mm}$-bore needle. The small cylinders of gel cut out by the needle were removed by suction. Each well received $10 \mu \mathrm{L}$ of antigen solution (standard curve) or blood serum; the samples were not diluted before the assay. The standard curve was prepared in accordance with Catty and Raykundalia (1988) using a goat IgG solution (50 $\mathrm{mg} / \mathrm{mL}$ ).

Hematocrit values were measured in accordance with the procedure of Kume and Tanabe (1993) to evaluate fluid intake effects $(50.23,49.65,51.43,51.67,48.21$, $49.89,50.11,49.03$, and $48.98 \%$ for frozen colostrum, lyophilized colostrum, H-IgG, M-IgG, L-IgG, HL-1d, HL2d, LL-1d, and LL-2d kids, respectively). No statistical differences were observed between groups.

From d 3 until 5, the kids were fed by milk replacer machine (Mini Robot, Divasa Farmavic, Sociedad Anónima) in accordance with Argüello et al., (2004a). Table 1 summarizes the group management systems.

All variables were normally distributed. The statistical analyses used to evaluate the effects of lyophilized colostrum feeding on IgG blood serum in kids was a GLM procedure with repeated measures between the frozen colostrum group and the lyophilized colostrum group. The effect of the IgG fed to kids during the colostrum feeding period on the IgG blood serum was evaluated using a GLM procedure with repeated measures using H-IgG, M-IgG, and L-IgG groups, and a posthoc Tukey analysis was performed. Finally, the effect of the timing of lyophilized colostrum meals was evaluated using a GLM procedure with repeated measures between HL-1d and HL-2d groups at high IgG concentration and between LL-1d and LL-2d at low IgG concentration (SPSS, 1988).

\section{RESULTS AND DISCUSSION}

None of the kids studied in any experiment displayed any detectable concentrations of IgG (the limit of detec- 
Table 2. Immunoglobulin G (least squares means) in blood serum of control group and lyophilized group kids.

\begin{tabular}{clcll}
\hline Time, h & FG kids ${ }^{1}$ & LG kids $^{1}$ & SEM & $P$ \\
\hline 0 & 0 & 0 & 0 & 0.009 \\
12 & 5.52 & 8.82 & 0.83 & \\
24 & 5.11 & 9.72 & 1.25 & \\
36 & 5.44 & 10.07 & 1.09 & \\
48 & 4.87 & 7.87 & 0.65 & \\
60 & 6.09 & 8.85 & 0.95 & \\
72 & 5.93 & 8.24 & 0.63 & \\
84 & 4.32 & 7.30 & 0.66 & \\
96 & 5.38 & 7.06 & 0.59 & \\
108 & 5.46 & 5.79 & 0.59 & \\
\hline
\end{tabular}

${ }^{1} \mathrm{FG}=$ Frozen colostrum group; $\mathrm{LG}=$ lyophilized colostrum group.

tion by radial immunodiffusion was $<0.11$ to $0.12 \mathrm{mg} /$ $\mathrm{mL}$ ) in the blood at birth (Tables 2, 3, and 4) in accordance with Constant et al. (1994) and Argüello et al. (2004c). Table 2 shows the results of the effect of feeding lyophilized colostrum vs. frozen colostrum (experiment 1). According to Table 1, the management and IgG amount received by frozen colostrum group kids and lyophilized colostrum group kids were the same, but the blood serum IgG concentration in both groups was statistically different $(P<0.009)$. At 12 and $108 \mathrm{~h}$ after birth, the IgG blood serum concentration was closer between groups, but at $36 \mathrm{~h}$ postpartum, lyophilized group kids had $85 \%$ more IgG blood serum concentration than did frozen colostrum group kids (5.44 and $10.07 \mathrm{mg} /$ $\mathrm{mL}$ in the frozen and lyophilized colostrum group kids, respectively). Contrary to the effect observed in Table 2, Klobasa et al. (1998) observed that immunoglobulins were absorbed with equal efficiency from frozen and lyophilized colostrum in newborn calves. The main difference between the 2 results was that, according to Klobasa et al. (1998), the lyophilized colostrum had the same IgG concentration as the frozen colostrum, but in the

Table 3. Immunoglobulin G (least squares means) blood serum in kids fed high, medium, and low concentrations ${ }^{1}$ of IgG from lyophilized paste.

\begin{tabular}{ccllll}
\hline Time & H-IgG & M-IgG & L-IgG & SEM & $P$ \\
\hline 0 & 0 & 0 & 0 & 0 & 0.001 \\
12 & $9.02^{\mathrm{a}}$ & $4.03^{\mathrm{b}}$ & $1.55^{\mathrm{b}}$ & 0.36 & \\
24 & $9.53^{\mathrm{b}}$ & $4.69^{\mathrm{b}}$ & $3.26^{\mathrm{b}}$ & 0.36 & \\
36 & $10.28^{\mathrm{a}}$ & $5.63^{\mathrm{b}}$ & $4.54^{\mathrm{b}}$ & 0.51 & \\
48 & $8.85^{\mathrm{a}}$ & $4.42^{\mathrm{b}}$ & $3.65^{\mathrm{b}}$ & 0.34 & \\
60 & $8.43^{\mathrm{a}}$ & $3.99^{\mathrm{b}}$ & $2.81^{\mathrm{b}}$ & 0.27 & \\
72 & $8.14^{\mathrm{a}}$ & $3.63^{\mathrm{b}}$ & $2.39^{\mathrm{b}}$ & 0.23 & \\
84 & $7.50^{\mathrm{a}}$ & $3.24^{\mathrm{b}}$ & $2.02^{\mathrm{b}}$ & 0.27 & \\
96 & $7.23^{\mathrm{a}}$ & $3.26^{\mathrm{b}}$ & $2.34^{\mathrm{b}}$ & 0.27 & \\
108 & $6.79^{\mathrm{a}}$ & $3.42^{\mathrm{b}}$ & $2.26^{\mathrm{b}}$ & 0.24 & \\
\hline
\end{tabular}

\footnotetext{
${ }^{\mathrm{a}, \mathrm{b}}$ Values with different superscripts differ at $P \leq 0.05$.

${ }^{1} \mathrm{H}-\mathrm{IgG}=$ High concentration of IgG in lyophilized paste, $\mathrm{M}-\mathrm{IgG}=$ medium concentration of IgG in lyophilized paste, and L-IgG = low concentration of IgG in lyophilized paste.
}

present study, the lyophilized colostrum paste had an IgG concentration higher than frozen colostrum (16.84 and $22.88 \mathrm{mg} / \mathrm{mL}$ of IgG for frozen and lyophilized paste colostrum, respectively). This may be the reason for the differences observed between experiments, and according to Muller and Ellinger (1981) or Stott and Fellah (1983), who reported that when compared on equal IgG mass, the amount of colostrum fed had less influence on IgG absorption than the IgG concentration. Thus colostrum, when correctly preserved by lyophilizing, can provide protection for kids.

Table 3 shows the effect of total IgG consumed by kids on IgG blood serum during the colostrum feeding period. The IgG blood serum in H-IgG kids was statistically higher than that in M-IgG and L-IgG kids. No statistical differences were found for IgG blood serum between MIgG and L-IgG kids, although L-IgG kids showed numerically lower IgG blood serum at all sample times. These results are in accordance with those of Abel Francisco and Quigley (1993) in calves or Dos Santos et al. (1994) working with Brazilian kids. On the contrary to that observed in the present experiment, Al-Jawad and Lees (1985) did not find statistical differences between lambs that received artificial colostrum with high $(139 \mathrm{mg} / \mathrm{mL})$ or low $(38 \mathrm{mg} / \mathrm{mL})$ IgG concentration.

Experiment 3 evaluated the effect of timing of lyophilized colostrum meals on IgG blood serum in new born kids at 2 different IgG concentrations. The HL-1d treatment presented statistically higher IgG blood serum concentrations than the HL-2d treatment at all sample times tested (Table 4). The amount of lyophilized colostrum paste was the same in both groups; consequently, the IgG concentration was higher in the HL-1d group. No statistical differences were found between LL-1d and LL-2d treatments, but LL-2d kids presented numerically lower IgG blood serum concentration at all sample times. Similar results are reported by Chen et al. (1999) in Nubian kids. The SEM values were very high and might have impeded the detection of statistical differences. High variability in IgG blood serum values have been previously reported in calves (Klobasa et al., 1988). Some artificial colostrum did not permit the immunoglobulin passive transfer (Argüello et al., 2003), which could explain the results related by Al-Jawad and Lees (1985). The feeding of colostrum in $1 \mathrm{~d}$ as opposed to $2 \mathrm{~d}$ gave better results when an equal IgG mass was used, and handling time was also reduced. In Spain, the standard practice is to have a 2-d colostrum feeding period, and the results shown in experiment 3 are useful for improving the management in dairy goat farms.

\section{CONCLUSIONS}

The IgG from lyophilized colostrum paste can be absorbed more efficiently than that from frozen colostrum. 
Table 4. Immunoglobulin G blood serum (least squares means) in kids fed high and low IgG concentrations. ${ }^{1}$

\begin{tabular}{|c|c|c|c|c|c|c|c|c|}
\hline \multirow[b]{2}{*}{ Time } & \multicolumn{4}{|c|}{ High IgG concentration } & \multicolumn{4}{|c|}{ Low IgG concentration } \\
\hline & HL-1d & HL-2d & SEM & $P$ & LL-1d & LL-2d & SEM & $P$ \\
\hline 0 & 0 & 0 & 0 & 0.011 & 0 & 0 & 0 & 0.252 \\
\hline 12 & 7.73 & 3.55 & 0.93 & & 3.28 & 1.22 & 0.24 & \\
\hline 24 & 6.96 & 4.49 & 0.85 & & 3.86 & 3.49 & 0.38 & \\
\hline 36 & 9.01 & 4.83 & 1.01 & & 3.68 & 3.29 & 0.62 & \\
\hline 48 & 9.43 & 4.43 & 1.21 & & 3.37 & 3.17 & 0.36 & \\
\hline 60 & 8.32 & 4.27 & 1.06 & & 3.43 & 2.70 & 0.22 & \\
\hline 72 & 5.93 & 3.84 & 0.41 & & 3.30 & 2.49 & 0.20 & \\
\hline 84 & 5.92 & 3.30 & 0.52 & & 3.39 & 2.13 & 0.33 & \\
\hline 96 & 5.82 & 3.45 & 0.49 & & 3.62 & 2.74 & 0.34 & \\
\hline 108 & 6.02 & 3.52 & 0.53 & & 3.53 & 2.06 & 0.28 & \\
\hline
\end{tabular}

${ }^{1} \mathrm{HL}-1 \mathrm{~d}=$ High concentration of IgG in lyophilized paste in $1 \mathrm{~d}$, HL-2d = high concentration of IgG in lyophilized paste in $2 \mathrm{~d}$, LL-1d = low concentration of IgG in lyophilized paste in $1 \mathrm{~d}$, and LL-2d = low concentration of IgG in lyophilized paste in $2 \mathrm{~d}$.

The amount of IgG intake by goat kids was clearly shown in the IgG blood serum concentration. If the same IgG mass is used, it is more expedient to feed the colostrum in $1 \mathrm{~d}$ rather than 2 . Lyophilizing colostrum is a suitable means of creating a colostrum bank with intact immunological qualities. Lyophilized colostrum powder is easy to transport, requires no special conditions for prolonged storage, and could be used to provide newborn kids with immunoglobulins. When using lyophilized vs. fresh/frozen colostrum the desired immunoglobulin mass should be fed on $\mathrm{d} 1$ rather than over a 2 -d period.

\section{ACKNOWLEDGMENTS}

The authors thank Heather R. Briggs for reviewing the English grammar of the paper.

\section{REFERENCES}

Abel Francisco, S. F., and J. D. Quigley, III. 1993. Serum immunoglobulin concentrations after feeding maternal colostrum plus colostral supplement to dairy calves. Am. J. Vet. Res. 54:1051-1054.

Al-Jawad, A. B., and J. L. Lees. 1985. Effects of ewe colostrum and various substitutes and the serum immunoglobulin concentration, gut closure process and growth rate of lambs. Anim. Prod. 40:123-127.

Argüello, A., N. Castro, and J. Capote. 2004a. Growth of milk replacer kids fed under three different managements. J. Appl. Anim. Res. 25:37-40.

Argüello, A., N. Castro, J. Capote, R. Ginés, F. Acosta, and J. L. López. 2003. Effects of refrigeration, freezing-thawing and pasteurization on IgG goat colostrum preservation. Small Rumin. Res. 48:135139.

Argüello, A., N. Castro, J. Capote, J. W. Tyler, and N. M. Holloway. 2004b. Effect of colostrum administration practices on serum IgG in goat kids. Livest. Prod. Sci. 90:235-239.

Argüello, A., N. Castro, M. J. Zamorano, A. Castroalonso, and J. Capote. 2004c. Passive transfer of immunity in kid goats fed refriger- ated and frozen goat colostrum and commercial sheep colostrum. Small Rumin. Res. 54:237-241.

Capote, J., N. Darmanin, J. V. Delgado, M. R. Fresno, and J. L. López. 1992. Agrupación Caprina Canaria Ed. Consejería de Agricultura y Pesca del Gobierno de Canarias, Canary Islands, Spain.

Catty, D., and C. Raykundalia. 1988. Gel immunodiffusion, immunoelectrophoresis and immunostaining methods. Pages 137-167 in Antibodies. D. Catty, ed. IRL Press, Oxford, UK.

Chen, J. C., C. J. Chang, H. C. Peh, and S. Y. Chen. 1999. Serum protein levels and neonatal growth rate of Nubian goat kids in Taiwan area. Small Rumin. Res. 32:153-160.

Constant, S. B., M. M. Leblanc, E. F. Klapstein, D. E. Beebe, H. M. Leneau, and C. J. Nunier. 1994. Serum immunoglobulin G concentration in goats kids fed colostrum or a colostrum substitute. JAVMA 205:1759-1762.

Dos Santos, G. T., D. A. Bertolini, F. Macedo, I. Prado, and E. Martins. 1994. Variabilidade em imunogloblina G (IgG) no colostro de cabra de primeira ordenha e absorcao intestinal de IgG pelos cabritos recém-nascidos. Arq. Biol. Tecnol. 37:285-292.

Guerrault, P. 1990. Apport de colostrum: Plusieurs methodes. La Chevre 180:30-31.

Husu, J., E. L. Syväoja, H. Ahola-Luttila, H. Kalsta, S. Sivelä, and T. U. Kosunen. 1993. Production of hyperimmune bovine colostrum against Campylobacter jejuni. J. Appl. Bacteriol. 74:564-569.

Klobasa, F., M. C. Goel, and E. Werhahn. 1998. Comparison of freezing and lyophilizing for preservation of colostrum as a source of immunoglobulins for calves. J. Anim. Sci. 76:923-926.

Kume, S., and S. Tanabe. 1993. Effect of parity on colostral concentrations of Holstein cows and value of colostrum as a mineral source for newborn calves. J. Dairy Sci. 76:1654-1660.

Mancini, G., A. O. Carbonara, and J. F. Heremans. 1965. Immunochemical quantitation of antigens by single radial immunodiffusion. Immunochemistry 2:235-254.

Muller, L. D., and D. K. Ellinger. 1981. Colostral immunoglobulin concentration among breeds of dairy cattle. J. Dairy Sci. 64:1727-1730.

Ramírez, A., A. Quiles, M. L. Hevia, F. Sotillo, and M. C. Ramírez. 1996. Influence of forced contact on the maternal-filial bond in the domestic goat after different periods of postpartum separation. Small Rumin. Res. 23:75-81.

SPSS User's Guide: Third Ed. 1988. SPSS Inc., Chicago, IL.

Stott, G. H., and A. Fellah. 1983. Colostral immunoglobulin absorption linearly related to concentration for calves. J. Dairy Sci. 66:1319-1328. 